This is the peer reviewed version of the following article:

Schneider, A., Andrade, J., Tanja-Dijkstra, K., White, M., \& Moles, D. R. (2016). The psychological cycle behind dental appointment attendance: a cross-sectional study of experiences, anticipations, and behavioral intentions. Community Dentistry and Oral Epidemiology, 44(4), 364-370, published in final form at 10.1111/cdoe.12221. This article may be used for non-commercial purposes in accordance with Wiley Terms and Conditions for Self-Archiving (http://olabout.wiley.com/WileyCDA/Section/id-820227.html\#terms).

\title{
The psychological cycle behind dental appointment attendance: A cross-sectional study of experiences, anticipations, and behavioral intentions
}

\author{
Annegret Schneider ${ }^{1}$, Jackie Andrade ${ }^{2,3}$, Karin Tanja-Dijkstra ${ }^{4}$, Mathew \\ White $^{5}$, David R. Moles ${ }^{3,6}$ \\ ${ }^{1}$ School of Health Sciences - University of Surrey \\ ${ }^{2}$ School of Psychology - Plymouth University \\ ${ }^{3}$ Cognition Institute - Plymouth University \\ ${ }^{4}$ VU Amsterdam, Netherlands \\ ${ }^{5}$ European Centre for Environment and Human Health \\ ${ }^{6}$ Plymouth University Peninsula Schools of Medicine and Dentistry
}

Corresponding Author: Annegret Schneider

Address: University of Surrey, 94 Hope Street, Glasgow, G2 6PH

Email: a.schneider@surrey.ac.uk

Figures and Tables: 1 Figure, 1 Table

Number of references: 38

Keywords: Psychosocial aspects of oral health; Behavioral Science; Dental services research; Anxiety 


\section{Abstract}

Objectives: This study explored a promising theoretical model to explain dental patients' experiences and planning behavior for future appointments. The model predicts that patients pass through a 'psychological cycle' when undergoing a course of dental care: past appointment experiences influence their anticipations for future dental visits, which in turn affect behavioral intentions to attend appointments.

Methods: Variables representing the hypothesized model stages and other potentially relevant context variables (dental anxiety, subjective oral health ratings, general anxiety, stress) were assessed by means of a cross-sectional online survey $(\mathrm{n}=311)$. Multiple regression analyses were calculated to estimate the model's fit while controlling for potentially confounding factors.

Results: Consistent with the hypothesized cycle, recollections of past appointment experiences influenced behavioral intentions to attend future appointments. This association was mediated by evaluations of prior visits and expectations for future appointments. The variables included within this model explained $42 \%$ of the variance in attendance intentions when controlling for the potential moderating effects of context variables.

Conclusions: The findings highlight the contribution of cognitive factors, such as evaluations and expectations, to patients' attendance intentions. This knowledge could help find ways to improve treatment expectations to foster better dental service utilization. 


\section{INTRODUCTION}

Missed healthcare appointments are costly and only partially remedied by reminders ${ }^{1}$. In dentistry, socioeconomic factors play a role in attendance behavior ${ }^{2-3}$, but less is known about psychological factors, despite compelling evidence that they contribute to oral health related behaviors more generally ${ }^{4}$. Even though oral health related quality of life studies $^{5-7}$ have started to consider physical, mental, and social aspects of oral health care, there has been less psychological research in dentistry than in medicine ${ }^{8}$.

Improved understanding of how dental patients' cognitions and feelings influence attendance should help to identify behavioral management techniques to improve dental attendance and, with that, oral health outcomes ${ }^{9}$. Growing attention to patient-reported outcome measures (PROMs) as health care quality criteria and calls for patient-centered care $^{10-11}$ and shared decision making ${ }^{12}$, acknowledge that understanding patients' views and concerns is important for appropriate oral health care and service utilisation ${ }^{13}$. This renders developing a model that explains dental patients' experiences and their influence on appointment uptake an urgent task.

To date, no satisfactory theory exists that fulfils those requirements. Health psychology models that consider social and cognitive factors have been applied to the dental context ${ }^{14-17}$, but they are not without criticism. Although from a pragmatic point of view, they can be useful frameworks for intervention development, the accuracy of their conceptual basis is less clear $^{18}$. For example, considerable overlap exists in key components between theories and empirical testing tends to focus on few model variables $^{19}$. The latter is partly due to the broad nature of those theories. The dental setting though involves distinct features, namely its foreseeable reoccurring appointment structure, and therefore requires tailored theories to suit the specific context. 
Clearly defined multi-stage cycle models are a step in the right direction, accounting for the dynamic nature of recurring engagement with dental care providers. Such models have had some success in explaining patterns of attendance behaviors in samples of people with dental anxiety ${ }^{20-23}$, but neglect cognitive factors. To go beyond behavioral models and specific patient groups, and advance our understanding of the underlying psychological components of dental attendance, this study draws on a psychological theory of well-being, the Dynamic Well-Being model (DWM) ${ }^{24}$.

The DWM offers a holistic approach to well-being, defining links between peoples' experiences, recollections, anticipations, intentions and behaviors. It therefore provides a good starting point for modeling how psychological appraisals of one event can influence feelings and behaviors relating to a later one. For a first application of this model to dentistry, the DWM was adapted by collapsing stages to improve its fit to the dental setting. Appointment outcomes (for example type of treatment) and experiences are closely related in time. Planning an appointment (for example booking it) is regarded as specific behavior and evaluations feed directly into future anticipations (for example expecting treatment or feeling anxious).

We hence proposed a psychological cycle behind dental appointment attendance that includes three sequential stages, which are linked as follows: at the experience stage, patients experience either dental check-ups or treatments. Anticipations as based on evaluations of prior experiences are then hypothesized to influence planning of future appointments and attendance behavior. Continuing the cycle, patients planning and attendance behavior affect their next appointment experience. This continuative relationship can be imagined as a spiral, whereby a person's first dental appointment influences their next one, but for simplicity is visualized as a cycle in Figure 1. 
The presented research tested the following hypotheses: A) Experiences, referring to previous dental procedures and associated feelings, affect the likelihood of arranging and attending future visits (behavior). We expect that more invasive treatments and negative emotions are associated with a lower chance of planning future appointments. B) This process is mediated by evaluations of past experiences and expectations of future ones (anticipation). We accounted in our analysis for the contribution of dental anxiety, general anxiety, stress, and perceived oral health status as these factors are known to be associated with avoidance of dental service uptake ${ }^{25}$.

\section{MATERIALS \& METHODS}

\section{Participants}

A total of 311 psychology students at a UK university, who are encouraged to take part in a range of studies of their choice to improve their understanding of research methods, participated in the study by completing an online questionnaire. As the focus of the current study was the exploration of basic mental processes, rather than epidemiological issues and patient representativeness, this convenience sample was deemed appropriate at this stage. Students are as much dental patients as other groups, varying on important dimensions such as treatment experiences and avoidance behavior. Non-clinical samples have been successfully used in prior dental and psychology research ${ }^{15-16}$.

Since the model has not been researched in dentistry before, no precise sample size could be calculated, but an $\mathrm{N}$ of approximately 300 participants was appropriate for the planned analysis ${ }^{26}$. The sample consisted of 262 female and 49 male participants. This proportion of $16 \%$ male participants is slightly below the number representative of psychology undergraduate students ${ }^{27}$. Participants' age ranged from 18 to 49 years (mean $=20.5 ; \mathrm{SD}=4.9)$ and there was no difference in mean age by gender $(\mathrm{U}=$ $5906.5 ; \mathrm{P}=0.357)$. 


\section{Procedure}

The study was conducted in accordance with the Declaration of Helsinki, briefing participants, obtaining informed consent, and ensuring data confidentiality and the right to withdraw at any time. Ethical approval was obtained from the Plymouth University Faculty of Health, Education and Society Research Ethics Committee. Participants were recruited using a participant pool advertising the study. If they agreed to participate, a link transferred them to the online survey. The questionnaire was available online between 27th September and 11th October 2013 and it took participants approximately 10 minutes to complete. The dropout rate was $3 \%$.

\section{Measures}

The assessment of the psychological cycle of dental experiences began by exploring how participants' previous dental appointments (past experience and evaluation) might influence their next one (future anticipations and behavioral intentions to attend appointments). The cycle was operationalized as following.

1) Experience Stage:

To encourage participants to think about their last appointment in detail, they were encouraged to describe the type of appointment they had and any relevant experiences. Specifically they were asked to choose from a list, including 'Check-up', 'Treatment', 'Dental hygiene', 'Orthodontics' or 'Others', the option which most closely reflected the nature of their visit. Participants rated how uneasy they felt and how much pain they recall experiencing, using rating scales ranging from zero ('not at all') to 10 ('extremely'). Such basic single items are routinely employed to capture pain experiences $^{28}$ and the two items represented a reliable scale (Spearman-Brown coefficients $\rho=0.78$ ). 


\section{2) Anticipation Stage:}

As noted above, we argue that when people make predictions about future events, they draw heavily on evaluations of relevant past events. Therefore, participants' evaluations of their most recent dental appointment were assessed with numerical ratings of six satisfaction statements adapted from the SERVQUAL questionnaire ${ }^{29}$, a scale measuring consumer perception of service quality. Rating scales ranged from zero ('strong disagreement') to 10 ('strong agreement') assessing issues such as satisfaction with tangibles, reliability, responsiveness, assurance and empathy of the dentist and the dental team (Cronbach's alpha coefficients $\alpha=0.93$ ). For measuring expected discomfort and pain, the same 11-point rating scales were used as for the experience stage $(\rho=0.83)$.

3) Behavior stage:

Due to the cross-sectional nature of the current study, dental patients' attendance behavior could not be observed directly and we therefore assessed behavioral intentions. Participants' dental planning and attendance intentions were operationalized by asking them to indicate on 11-point scales ranging from zero ('not likely at all') to 10 ('extremely likely') the likelihood that they will a) avoid booking their next appointment, and b) postpone a planned visit. Those two questions formed a reliable scale $(\rho=0.81)$ and were summed to provide a composite score, which is subsequently referred to as the 'behavioral intentions to attend appointments'.

Additionally, participants completed the Modified Dental Anxiety Scale ${ }^{30-31}$ (MDAS), a validated five-item questionnaire with an answering response scale from one ('not anxious') to five ('extremely anxious'). The MDAS represents a short and easy to administer dental anxiety assessment tool frequently used in dental research ${ }^{32}$. 
Participants indicated their age and gender as well as their general well-being, in particular negative affect as assessed with the 21-item Depression-Anxiety-StressScale $^{33}$ (DASS 21). This short, validated version of the DASS assesses symptoms of general anxiety, depression and stress on a scale from zero ('did not apply to me at all') to three ('applied to me very much'). Finally, a single item scale was used to gather participants' own subjective oral health status from zero ('worst imaginable oral health state') to 10 ('best imaginable oral health state').

\section{Statistical Analysis}

The data were analyzed using SPSS Statistics 21 software. Descriptive statistics of participants' demographic characteristics were calculated. Since items assessing experiences, evaluations, anticipations, and behavioral intentions constituted nonvalidated scales, their homogeneity was examined using Cronbach's alpha coefficients $(\alpha)$ for multi-item questionnaires and Spearman-Brown estimates $(\rho)$ for 2-item scales as recommended by Eisinga et al. ${ }^{34}$.

The proposed model of dental experiences was examined by testing the sequence of its stages computing sequential regression analyses. This stepwise approach allows for testing the hypothesized mediation effects with the cross-sectional data at hand, entering predictor variables into the regression model one at a time ${ }^{35}$. Variables representing the cycle stages correlated with each other, but there was no reason to suspect significant multicollinearity between the independent variables (Variance Inflation Factors < 4), meeting a precondition for regression analyses.

The outcome variable was 'behavioral intentions to attend appointments' and its preceding stages were added in sequential steps. To control for potential influences of dental anxiety, subjective oral health ratings, general anxiety and stress on planning and attendance intentions, those context variables were entered as a first step into the 
regression model. Then the experience stage was added assuming that previous dental experiences would influence a person's likelihood to plan future appointments. Finally, the anticipation stage was entered in the model, which was hypothesized to have a significant effect on planning and attendance intentions and to mediate the effect of the prior stage. An alpha level of $\mathrm{P}<0.05$ was applied for statistical significance tests.

\section{RESULTS}

Table 1 provides an overview of the multiple regression analysis predicting the dependent variable 'behavioral intentions to attend appointments'.

Only dental anxiety and oral health ratings affected planning and attendance intentions, with greater dental anxiety and perceived lower oral health associated with lower behavioral intentions to attend appointments. General anxiety and stress had no effects. The context factors explained $20 \%$ of the variance of participants' behavioral intentions.

In the next step, items reflecting the experience stage of the theoretical model were added to the statistical model. Specifically, the type of appointment (check-up, treatment, oral hygiene, orthodontics) and associated feelings were added and both were significant predictors of planning and attendance intentions. Undergoing treatment at their last appointment decreased participants' tendency to avoid their next appointment whereas remembering pronounced discomfort and pain made avoidance more likely. Considering past experiences increased the model's explanatory value by $12 \%$ and mediated the effects associated with dental anxiety and oral health on participants' behavioral intentions.

Finally, items from the anticipation stage of the theoretical model were added to the regression, specifically participants' evaluations of their last appointment experience and anticipations for their next one. Including the anticipation stage into the model 
further improved its explanatory value, explaining an additional $10 \%$ of the variance of planning and attendance intentions. Low evaluation scores for previous appointments and high negative anticipations of future visits significantly decreased the likelihood of planning and attendance future appointments. Importantly for the theoretical model, there was also evidence that the variables entered at the anticipation stage mediated the influence of those entered at the experience stage on future behavioral intentions, as all 'experience stage' items were now rendered non-significant. The overall model, including context factors such as dental anxiety and oral health ratings and both cycle stages, explained $42 \%$ of the variance of participants' behavioral intentions.

\section{DISCUSSION}

The current study demonstrated the importance of patients' evaluations and anticipations for intentions to engage in dental attendance, over and above what patients recall occurring during past appointments. Experiences did not directly influence future behavioral intentions, but it was rather their evaluation that was the proximal predictor of future actions. This finding supports previous work that has also stressed the importance of psychological factors in dentistry ${ }^{4-7,20-23}$. In line with theoretical predictions based on the Dynamic Well-Being Model (DWM) ${ }^{24}$, results are consistent with dental experiences following a characteristic cycle of sequential stages that integrates behavioral, cognitive and emotional aspects.

The multiple regression analysis certifies the model's statistical significance and attests considerable explanatory value, shedding light on variance in patients' intentions concerning future dental service uptake. It supports the proposed stage sequence, where past experiences influence future behavioral intentions, via patients' evaluations of prior visits and expectations about future ones. The finding that not necessarily the event itself is decisive for future behavioral intentions stresses the importance of cognitive processes for patients' dental attendance, as suggested by Armfield ${ }^{21-22}$. This 
relationship helps explain the paradoxical findings that negative treatment experiences are predictive of dental anxiety ${ }^{36}$, which is associated with avoidance behavior ${ }^{20-23}$, yet some patients with negative experiences do not exhibit any subsequent difficulties ${ }^{37}$. The influence of patients' evaluations of prior visits and expectations for future visits on future planning and attendance intentions was demonstrated even when taking into account known influences such as dental anxiety and perceived oral health. Those findings highlight the importance of considering cognitive processes when planning interventions to improve service utilization.

Despite the encouraging support for the theoretical model, we also recognize that the study has a number of limitations. For instance, due to its cross-sectional nature, assessing actual attendance behavior was not feasible and there is a chance that memory bias $^{38}$ affected participants' recollections of previous experiences. Although being able to test the hypothesized mediation effects ${ }^{35}$, this type of data does not permit conclusions about causality, which should be tested in future longitudinal research on attendance, postponement and cancellations. Nevertheless, an advantage of this approach at this stage was that even people who avoid dental visits or completely dropped out of a dental care system could participate, providing a versatile sample to test the proposed theoretical model. This would not have been possible if a precondition for participation was a scheduled dental appointment.

We also recognize that there are potential issues with the measures we used to assess constructs at each of the model's stages. As this was a first exploration of the model within dentistry, there were no validated measures representing the cycle stages. Further work is thus needed to establish relevant scales to measure these factors, which would facilitate future research on the psychological determinants of dental attendance and avoidance. 
Finally, we also acknowledge that the present sample of students is not representative of all dental patients. Nonetheless, the primary aim here was to test the model's potential applicability to a dental context, which we believe we have done. We recognize that the next step is to test its generalizability in more representative samples of dental patients. To develop the model further, future research should examine whether and if so to what degree the observed relationships between constructs hold up in a general public sample of dental patients with a wider variability in key variables.

To conclude, the presented model extends existing theories that try to explain dental patients' experiences and attendance behaviors, such as Armfield's and Berggren's dental anxiety cycle models $\mathrm{s}^{20-23}$, incorporating cognitive and additional emotional variables as suggested by health psychology theories ${ }^{14,18-19}$. A key contribution of the proposed psychological cycle of dental experiences is its broader applicability to all dental patients, instead of solely anxious ones, while explaining patients' experiences and behavior at different time points relative to appointments. Understanding psychological influences on intentions to attend dental appointments should help to find ways to strengthen attendance motivation and foster appropriate dental service utilization. 


\section{ACKNOWLEDGMENTS}

The presented research was financially supported by Plymouth University by means of a $\mathrm{PhD}$ studentship, as the study was part of a $\mathrm{PhD}$ research program. No external funding was obtained.

\section{CONFLICT OF INTEREST STATEMENT}

The authors certify that they have no affiliations with or involvement in any organization or entity with any financial or non-financial interests in the subject matter discussed in this manuscript. 


\section{REFERENCES}

1 Gurol-Urganci I, De Jongh T, Vodopivec-Jamsek V, Atun R, Car J. Mobile phone messaging reminders for attendance at healthcare appointments. Cochrane Database Syst Rev 2013;12:CD007458.

2 Iben P, Kanellis MJ, Warren J. Appointment-keeping behavior of Medicaidenrolled pediatric dental patients in eastern Iowa. Pediatr Dent 2000;22:325-329.

3 Greenberg BJ, Kumar JV, Stevenson H. Dental case management: increasing access to oral health care for families and children with low incomes. J Am Dent Assoc 2008;139:1114-1121.

4 Clarkson JE, Young L, Ramsay CR, Bonner BC, Bonetti D. How to influence patient oral hygiene behavior effectively. J Dent Res 2009;88:933-937.

5 Baker SR. Testing a Conceptual Model of Oral Health: a Structural Equation Modeling Approach. J Dent Res 2007;86:708-712.

6 Locker D, Clarke M, Payne B. Self-perceived Oral Health Status, Psychological Well-being, and Life Satisfaction in an Older Adult Population. J Dent Res 2000;79:970-975.

7 Sischo L, Broder HL. Oral health-related quality of life: what, why, how, and future implications. J Dent Res 2011;90:1264-1270. 
8 Baker SR. In: Forshaw M, Sheffield D, editors: Health Psychology in Action. Applying Health Psychology to Dentistry: "People, Not Teeth”, Chichester: John Wiley \& Sons Ltd, 2013; 1-16.

9 Renz A, Ide M, Newton JT, Robinson P, Smith D. Psychological interventions to improve adherence to oral hygiene instructions in adults with periodontal diseases. Cochrane Database Syst Rev 2007;18:CD005097.

10 Palfreyman S. Patient-reported outcome measures and how they are used. Nursing Older People 2011;23:31-36.

11 Mills I, Frost J, Moles DR, Kay E. Patient-centred care in general dental practice: sound sense or soundbite? Brit Dent J 2013;215(2):81-85.

12 Elwyn G. Implementing shared decision making in the NHS and patients should be the first step in giving patients choice. BMJ 2010;341:971-975.

13 Abrahamsson KH, Ohrn K, Hakeberg M. Dental beliefs: factor structure of the revised dental beliefs survey in a group of regular dental patients. Eur J Oral Sci 2009; 117:720-727.

14 Hollister MC, Anema MG. Health behavior models and oral health: a review. J. Dent. Hyg. 2004;78:6.

15 Lavin D, Groarke A. Dental floss behaviour: A test of the predictive utility of the Theory of Planned Behaviour and the effects of making implementation intentions. Psychol. Health Med. 2005;10:243-252. 
16 Schüz B, Sniehotta FF, Wiedemann A, Seemann R. Adherence to a daily flossing regimen in university students: effects of planning when, where, how and what to do in the face of barriers. J. Clin. Periodontol. 2006;33:612-619.

17 Jönsson B, Baker SR, Lindberg P, Oscarson N, Ohrn K. Factors influencing oral hygiene behaviour and gingival outcomes 3 and 12 months after initial periodontal treatment: an exploratory test of an extended Theory of Reasoned Action. J. Clin. Periodontol. 2012;39:138-144.

18 Ogden J. Some problems with social cognition models: A pragmatic and conceptual analysis. Heal. Psychol. 2003;22:424-428.

19 Armitage CJ, Conner M. Social cognition models and health behaviour: A structured review. Psychology \& Health 2000;15:173-189.

20 Weinstein P. Breaking the worldwide cycle of pain, fear, and avoidance: Uncovering risk factors and promoting prevention for children. Ann Behav Med 1990;12: 141-147.

21 Armfield JM, Stewart JF, Spencer AJ. The vicious cycle of dental fear: exploring the interplay between oral health, service utilization and dental fear. BMC Oral Health 2007;7:1-15.

22 Armfield JM. What goes around comes around: revisiting the hypothesized vicious cycle of dental fear and avoidance. Community Dent Oral Epidemiol 2013;41:279-287.

23 Berggren U, Meynert G. Dental fear and avoidance: causes, symptoms, and consequences. J Am Dent Assoc 1984;109:247-251. 
24 Dolan P, White M. Dynamic Well-Being: Connecting Indicators of what People Anticipate with Indicators of what they Experience. Soc Indic Res 2006;75:303333.

25 Hill KB, Chadwick B, Freeman R, O’Sullivan I, Murray JJ. Adult Dental Health Survey 2009: relationships between dental attendance patterns, oral health behaviour and the current barriers to dental care. Brit Dent J 2013;214:25-32.

26 Jones SR. An introduction to power and sample size estimation. Emergency Medicine Journal 2003;20: 453-458.

27 Sander P. Gender, psychology students and higher education. Psychology Learning and Teaching 2007;6:33-36.

28 Newton JT, Buck DJ. Anxiety and pain measures in dentistry: a guide to their quality and application. J Am Dent Assoc 2000;131: 1449-1457.

29 Jain SK, \& Gupta G. Measuring service quality: SERVQUAL vs. SERVPERF scales. Vikalpa 2004;29:25-37.

30 Humphris GM, Dyer T, Robinson PG. The modified dental anxiety scale: UK general public population norms in 2008 with further psychometrics and effects of age. BMC Oral Health 2009;26:9-20.

31 Corah NL. Development of a dental anxiety scale. J Dent Res 1969;48:596. 
32 Dailey YM, Humphris GM, Lennon M. Reducing patients' state anxiety in general dental practice: a randomized controlled trial. J Dent Res 2002;81:319322.

33 Henry JD, Crawford JR. The short-form version of the Depression Anxiety Stress Scales (DASS-21): construct validity and normative data in a large nonclinical sample. Brit J Clin Psychol 2005;44:227-239.

34 Eisinga R, Grotenhuis M, Pelzer B. The reliability of a two-item scale: Pearson, Cronbach or Spearman-Brown? International Journal of Public Health 2013; 58:637-642.

35 Baron RM., Kenny D. The Moderator-Mediator Variable Distinction in Social The Moderator-Mediator Variable Distinction in Social Psychological Research: Conceptual, Strategic, and Statistical Considerations. J. Pers. Soc. Psychol. 1986;51:1173-1182.

36 Eli I, Uziel N, Baht R, Kleinhauz M. Antecedents of dental anxiety: learned responses versus personality traits. Community Dent Oral Epidemiol 1997;25:233-237.

37 De Jongh A, Aartman I, Brand N. Trauma-related phenomena in anxious dental patients. Community Dent Oral Epidemiol 2003;31:52-58.

38 Creswell JW. Research design: Qualitative, quantitative, and mixed methods approaches. 3nd edition. Thousand Oaks: Sage Publications;2009. 
Table 1. Multiple regression model of the Psychological Dental Cycle controlling for dental anxiety, general anxiety, stress and subjective oral health ratings (dependent variable 'Behavioral intentions')

\begin{tabular}{|c|c|c|c|c|c|c|}
\hline Stages & B $(95 \%$ CI $)$ & SE B & $\beta$ & $\mathrm{P}$ & $\begin{array}{c}\mathrm{R}^{2} \\
\text { change }\end{array}$ & $\begin{array}{c}\mathrm{F} \text { model } \\
\text { test }\end{array}$ \\
\hline \multicolumn{7}{|l|}{0 Context factors: } \\
\hline $\begin{array}{l}\text { MDAS } \\
\text { Oral health ratings } \\
\text { DAS21-Anxiety } \\
\text { DAS21-Stress }\end{array}$ & $\begin{array}{c}0.35(0.23,0.47) \\
-0.86(-1.25,-0.48) \\
-0.04(-0.25,0.16) \\
0.05(-0.08,0.18)\end{array}$ & $\begin{array}{l}0.06 \\
0.20 \\
0.10 \\
0.07\end{array}$ & $\begin{array}{c}0.32 \\
-0.23 \\
-0.03 \\
0.05\end{array}$ & $\begin{array}{c}<0.001 \\
<0.001 \\
0.69 \\
0.47\end{array}$ & $0.20^{* * *}$ & $19.278 * * *$ \\
\hline \multicolumn{7}{|l|}{1 Context + Experience: } \\
\hline $\begin{array}{l}\text { MDAS } \\
\text { Oral health ratings } \\
\text { DAS21-Anxiety } \\
\text { DAS21-Stress }\end{array}$ & $\begin{array}{c}0.16(0.03,0.28) \\
-0.49(-0.87,-0.12) \\
-0.05(-0.24,0.14) \\
0.06(-0.06,0.18)\end{array}$ & $\begin{array}{l}0.06 \\
0.19 \\
0.10 \\
0.06\end{array}$ & $\begin{array}{c}0.14 \\
-0.13 \\
-0.03 \\
0.06\end{array}$ & $\begin{array}{l}0.01 \\
0.01 \\
0.60 \\
0.35\end{array}$ & \multirow[t]{2}{*}{$0.12 * * *$} & $18.009 * * *$ \\
\hline $\begin{array}{l}\text { Past appointment type } \\
\text { Treatment } \\
\text { Dental hygiene } \\
\text { Orthodontics } \\
\text { Negative past experience }\end{array}$ & $\begin{array}{c}-1.57(-3.09,-0.05) \\
-0.35(-2.92,2.22) \\
1.39(-1.50,4.27) \\
0.50(0.36,0.64)\end{array}$ & $\begin{array}{l}0.77 \\
1.31 \\
1.47 \\
0.07\end{array}$ & $\begin{array}{r}-0.11 \\
-0.01 \\
0.05 \\
0.44\end{array}$ & $\begin{array}{c}0.04 \\
0.79 \\
0.35 \\
<0.001\end{array}$ & & \\
\hline $\begin{array}{l}2 \text { Context }+ \text { Experience }+A \\
\text { MDAS } \\
\text { Oral health ratings } \\
\text { DAS21-Anxiety } \\
\text { DAS21-Stress }\end{array}$ & $\begin{array}{l}\text { tion: } \\
0.01(-0.11,0.13) \\
-0.18(-0.54,0.18) \\
-0.01(-0.19,0.17) \\
0.05(-0.06,0.17)\end{array}$ & $\begin{array}{l}0.06 \\
0.18 \\
0.09 \\
0.06\end{array}$ & $\begin{array}{c}0.01 \\
-0.05 \\
-0.01 \\
0.06\end{array}$ & $\begin{array}{l}0.88 \\
0.32 \\
0.93 \\
0.37\end{array}$ & $0.10^{* * *}$ & $21.561 * * *$ \\
\hline $\begin{array}{l}\text { Past appointment type } \\
\text { Treatment } \\
\text { Dental hygiene } \\
\text { Orthodontics } \\
\text { Negative past experience }\end{array}$ & $\begin{array}{l}-0.35(-1.81,1.12) \\
-0.11(-2.51,2.29) \\
1.53(-1.16,4.21) \\
0.08(-0.10,0.25)\end{array}$ & $\begin{array}{l}0.74 \\
1.22 \\
1.37 \\
0.09\end{array}$ & $\begin{array}{l}-0.03 \\
-0.00 \\
0.05 \\
0.07\end{array}$ & $\begin{array}{l}0.64 \\
0.93 \\
0.27 \\
0.40\end{array}$ & & \\
\hline $\begin{array}{l}\text { Positive past Evaluation } \\
\text { Future anticipation }\end{array}$ & $\begin{array}{c}-0.06(-0.11,-0.02) \\
0.52(0.35,0.68)\end{array}$ & $\begin{array}{l}0.02 \\
0.08\end{array}$ & $\begin{array}{l}-0.13 \\
0.49\end{array}$ & $\begin{array}{c}0.01 \\
<0.001\end{array}$ & & \\
\hline
\end{tabular}

$* \mathrm{~B}=$ Regression Coefficient, $\mathrm{CI}=$ Confidence Interval, $\mathrm{SE}=$ Standard Error, $\beta=$ Standardized Estimate, $\mathrm{P}=$ Significance, $* * * \mathrm{P} \leq 0.001 ; * * \mathrm{P} \leq 0.01 ; * \mathrm{P} \leq 0.05$, MDAS $=$ Modified Dental Anxiety Scale, DAS21 = Depression-Anxiety-Stress-Scale. 


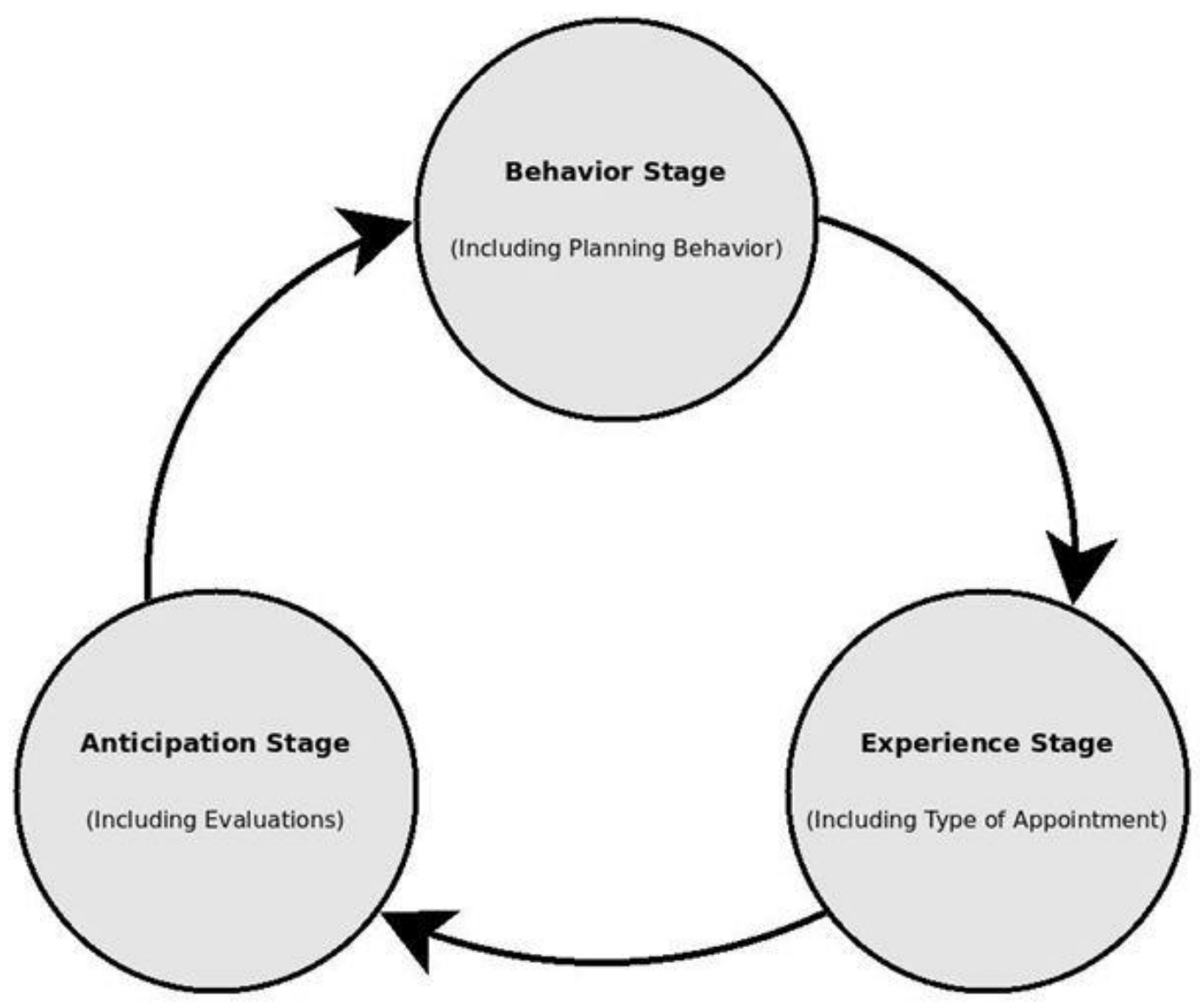

Figure 1. Model of the Psychological Dental Cycle 